\title{
The management of severe hypodontia. Part 2: bone augmentation and the provision of implant supported prostheses
}

\author{
K. Durey, ${ }^{* 1}$ L. Carter ${ }^{2}$ and M. Chan ${ }^{3}$
}

\section{VERIFIABLE CPD PAPER}

The first part of this series on severe hypodontia discussed the assessment of patients and factors to consider when treatment planning for the provision of conventional restorative solutions. This article discusses the provision of implant supported prostheses in the severe hypodontia patient who typically presents with inadequate bone volume and other associated dental and craniofacial anomalies. The role of bone augmentation to facilitate implant placement is discussed, in addition to prosthesis design and long-term maintenance. With careful case selection and planning most patients with severe hypodontia can be rehabilitated effectively, both functionally and aesthetically, with implant supported prostheses. In complex cases the involvement of a multidisciplinary team is needed to improve outcome. It should be highlighted that these patients will require ongoing follow up, maintenance and retreatment procedures over their lifetimes.

\section{INTRODUCTION}

The first part of this two-part series covered the factors that should be considered when treatment planning for the severe hypodontia patient. Treatment options discussed included the use of composite to reshape both retained primary teeth and permanent teeth, tooth supported conventional and adhesive fixed bridgework and conventional removable prosthodontics. Implant supported prostheses may be an option, however, their provision is unlikely to be straightforward and considerations specific to this are discussed in this paper.

\section{IMPLANT SUPPORTED PROSTHESES}

Implant supported prostheses may range from single crowns and fixed bridges to removable overdentures, depending on the pattern of missing teeth and bone availability. As stated previously in part one, the ideal tooth position in terms of appearance, function and occlusal relationships should be established through the use of articulated study models and aesthetic previews. Appropriate imaging, usually involving a

${ }^{1} \mathrm{SpR}$ in Restorative Dentistry, ${ }^{2}$ Consultant in Oral and Maxillofacial Surgery, ${ }^{3}$ Consultant in Restorative Dentistry, Leeds Dental Institute, Clarendon Way, Leeds, LS2 9LU

${ }^{*}$ Correspondence to: Kathryn Durey

Email: kathryndurey@hotmail.co.uk

\section{Refereed Paper}

Accepted 30 July 2013

DOI: 10.1038/sj.bdj.2014.5

${ }^{\circ}$ British Dental Journal 2014; 216: 63-68 cone bean CT scan with guide stents in situ will reveal the bone quantity and quality available for implant placement.

\section{BONE AUGMENTATION}

As previously discussed, in severe hypodontia patients, the absence of permanent teeth results in restricted alveolar growth. ${ }^{1}$ If implants are to be placed and there is a lack of bone, bone augmentation techniques may facilitate this treatment option (Fig. 1).

Materials available for bone augmentation include autogenous bone, sourced from the patient themselves; xenografts, sourced from animals; synthetic alloplastic materials or allograft (human donor) bone products. These materials have been used alone or in combinations. ${ }^{2}$ It has been generally considered that autogenous bone was the grafting material of choice, however, there is increasing evidence that in appropriate situations, bone substitutes can achieve good results, ${ }^{3}$ while avoiding the need for harvesting from a donor site and decreasing morbidity.

Depending on the type of graft material used and the area to be augmented, different forms of onlay or inlay grafting may be used. ${ }^{3}$ Onlay grafting involves placing particulate graft material on to the surface of the preexisting alveolar ridge or solid blocks of material secured by titanium fixation screws. Alternatively, the alveolar ridge can be split and grafting material packed into the space created, as an interpositional graft. ${ }^{4}$

The placement of implants can take place at the same time as bone augmentation in a one-stage procedure, or it can be delayed until a period of healing has taken place. A two-stage procedure requires a further surgical episode for the patient and requires additional healing time. There is limited evidence to support one approach over another, however, it has been suggested that where primary stability is poor or significant augmentation has taken place, a two-stage approach may reduce the risk of implant failure and complications. ${ }^{5}$

\section{Mild-moderate horizontal bone defects}

Where only a small change in bucco-lingual dimension of bone is required to facilitate implant placement guided bone regeneration at the time of implant placement can be highly predicable. In this situation there should be good primary stability for predictable results.

Autogenous or particulate bone substitute materials can be packed around the implant at sites of bony dehiscence ${ }^{6}$ and covered by a membrane that prevents the in-growth of soft tissue. There are a number of synthetic and xenograft materials available, which can act as bone substitutes and promote osseoconduction and bony infill. Additionally, a limited volume of autogenous bone chips can be harvested locally at the time of surgery. This can be done by chiselling or scraping fragments of bone at the surgical site or by aspirating bone particles created during preparation of the osteotomy site into a bone trap. Due to the potential for 


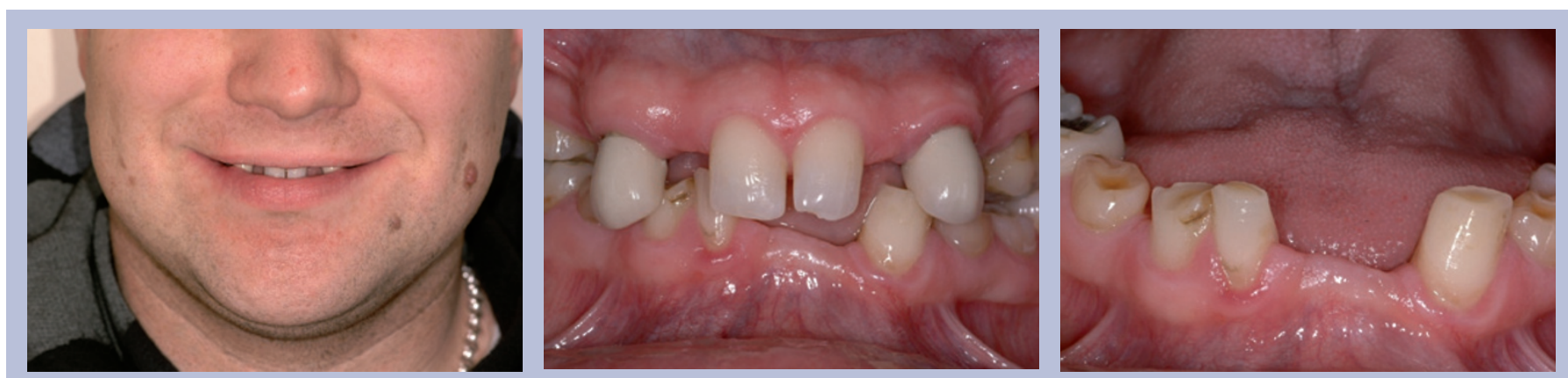

Figs 1 a-c 33 year old with 13 developmentally absent adult teeth, microdontia, tooth wear, 6 retained primary teeth and excessive spacing

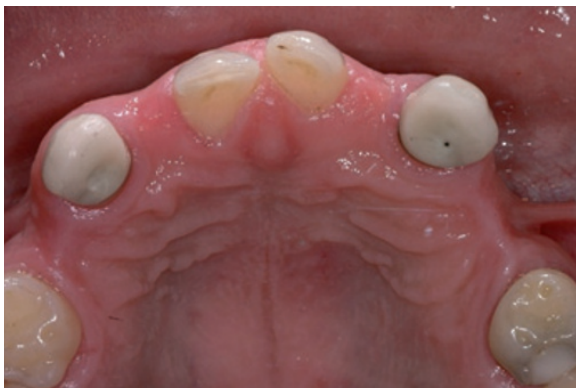

Fig. 1d Previously treated with crowns to 13, 23 and a removable partial denture

bacterial contamination, the use of the bone traps is somewhat controversial. If they are used, a stringent aspiration protocol should be followed: their use should be confined to the surgical site and a separate aspirator used to remove saliva from the back of the mouth. ${ }^{7-9}$

As with all surgery, planning of bone augmentation procedures should involve some risk assessment. Where defects are small, the risk of morbidity associated with a donor site can be avoided by the use of bone substitutes. However, where more bone volume is required, other options should be considered as large volumes of particulate material are structurally unstable and attempts to augment large defects in this manner will be unsuccessful.

\section{Moderate-severe horizontal bone defects with minimal vertical gain}

Block onlay grafts provide excellent structural stability and have the potential to act as a scaffold for the regeneration of the alveolar ridge. Intraoral donor sites such as the mental symphysis and the mandibular ramus are frequently used. Depending on patient compliance, this surgery can be completed without the need for a general anaesthetic. There is, however, a limit to the amount of bone that can be harvested intraorally and the surgery can be associated with some morbidity such as swelling, haemorrhage, infection and neural disturbance. The latter is most likely to occur when harvesting from the chin and although in the majority of cases this is temporary, there is small risk of permanent paraesthesia.

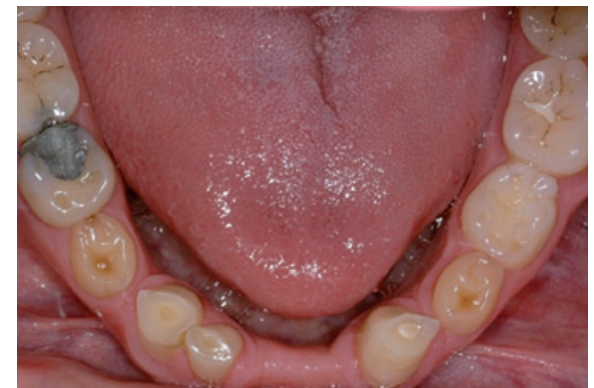

Fig. 1e Lack of alveolar bone width in the lower anterior region

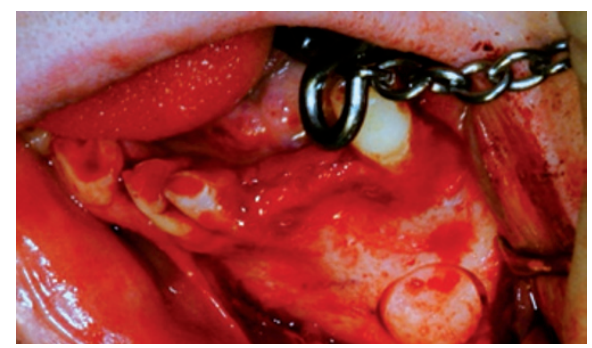

Fig. 2a Patient seen in Figure 1, undergoing harvesting of a cortico-cancellous bone block from the mental region, using a trephine

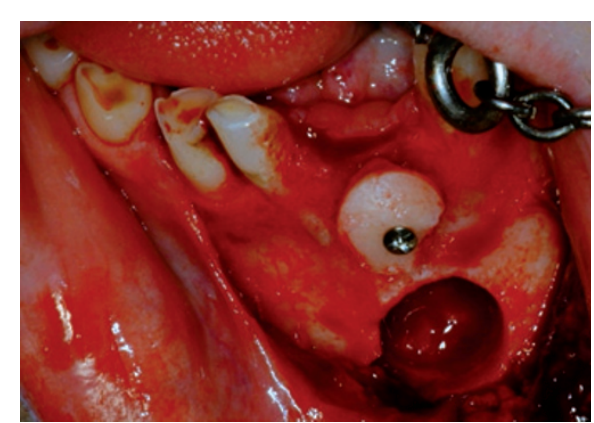

Fig. 2b Block secured to recipient site with fixation screw, after decortication

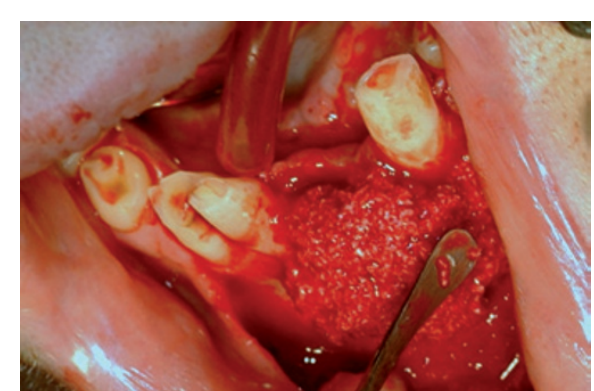

Fig. 2c Cancellous bone chips packed around block and covered with particulate xenograft

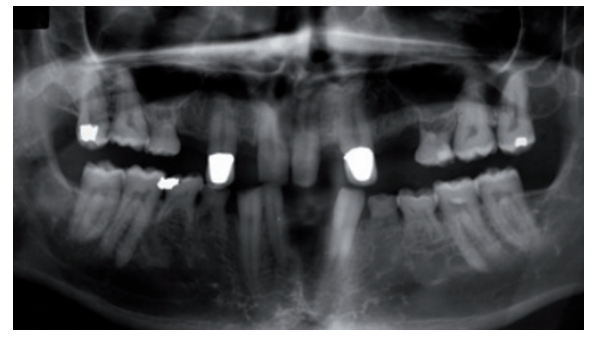

Fig. If Panoramic radiograph demonstrating inadequate bone height in the upper premolar region. Note the distal angulation of the $\mathbf{3 3}$

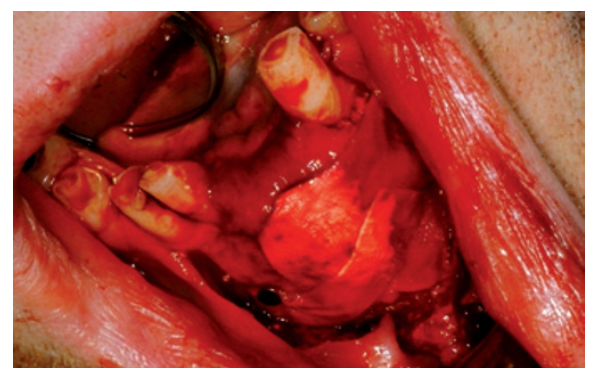

Fig. 2d Double layer of collagen membrane fixed with titanium tacks

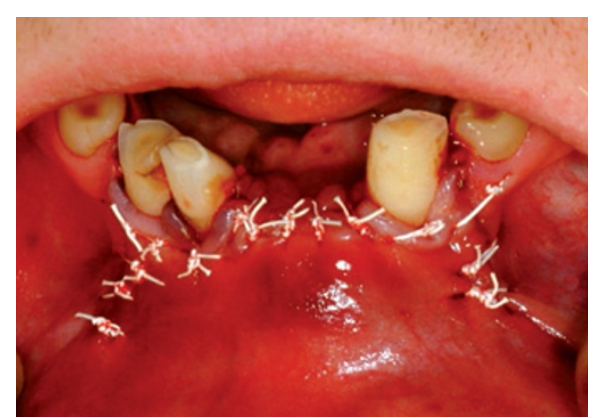

Fig. 2e Careful soft tissue closure after releasing periosteum

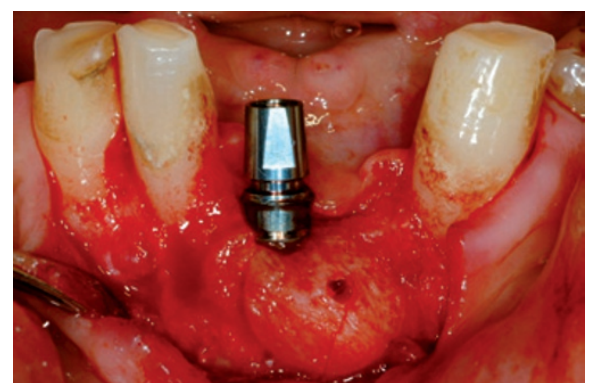

Fig. $2 f$ Placement of dental implant into grafted area after four months healing, avoiding the root of the distally angulated $\mathbf{3 3}$ 


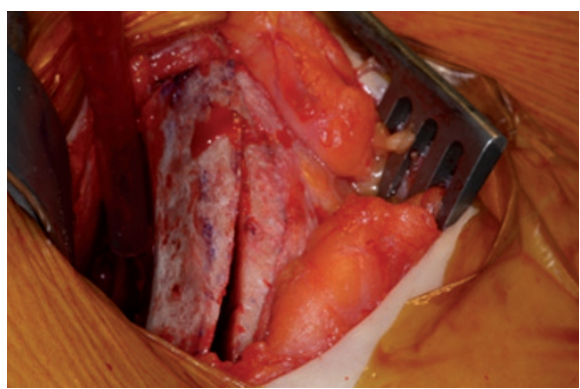

Fig. 3a Access to iliac crest and initial bone cuts

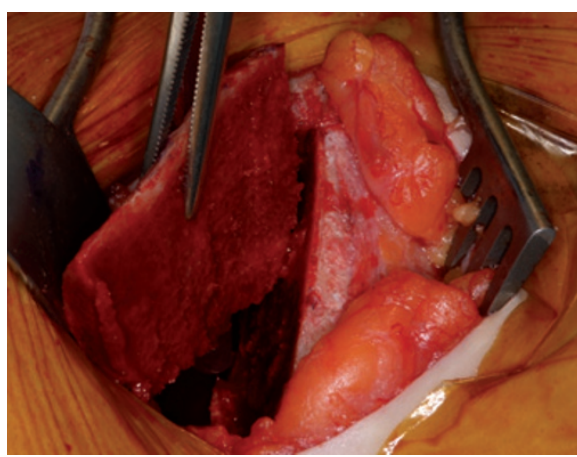

Fig. 3b Large bone block removed with aid of chisels and bone saw

Loss of vitality of the lower incisor teeth can also occur where bone cuts are made too close to the root apices. ${ }^{10,11}$

Intraoral block grafts (Fig. 2) are generally harvested using a fissure bur, trephine or more recently piezo surgery. ${ }^{12}$ The block is then contoured and fixed rigidly to the alveolar ridge with a titanium fixation screw, ensuring close contact between the recipient site and the graft. Some perforation of the cortical plate of the recipient site (decortication) is generally considered to be advantageous to bony integration. Particulate bone and biomaterials may also be packed around the block graft and the use of a collagen membrane can further help to stabilise these and prevent soft tissue ingrowth. ${ }^{2,13}$

When the width of the ridge is significantly increased, soft tissue closure may be difficult. Achieving full coverage of the site and ensuring that there is minimal tension on closure is key to minimising the risk of soft tissue dehiscence and graft failure. If initial incisions are made palatal to the crest of the ridge and periosteal release is carried out to mobilise the soft tissue flap, this problem can be minimised. However, advancing the mucosa from the buccal aspect may mean that the future implants have a lack of buccal keratinised mucosa, which is less than ideal for the health and stability of the peri-implant tissues. This situation can be corrected at a subsequent surgical intervention, for example one option may be to place a connective tissue graft at the time of implant exposure.

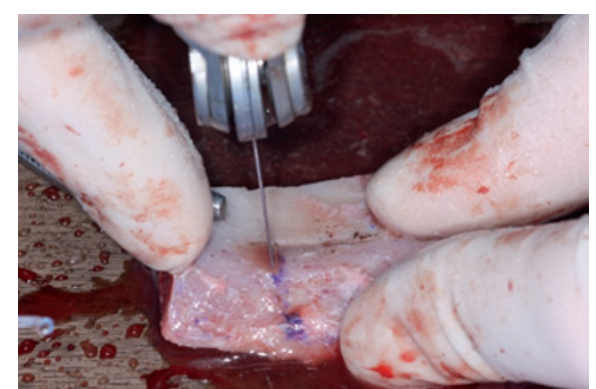

Fig. 3c Customisation of bone block to fit residual alveolar ridge by sectioning

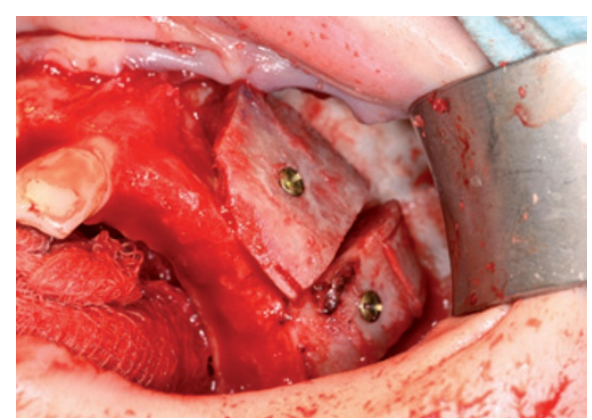

Fig. 3d Bone blocks secured with titanium fixation screws

Following surgery, trauma to the area and pressure on the graft should be avoided. This requires careful assessment and adjustment of the patients' removable prosthesis or a period without a prosthesis may be advised. After a four-month healing period, the fixation screws can be removed and dental implants placed in the grafted alveolar ridge.

\section{Severe horizontal and vertical defects}

Augmentation using bone from extra oral donor sites, typically the iliac crest, can be considered where large volumes of bone are required. This necessitates a general anaesthetic, in-patient management and involvement of the maxillofacial team. Surgery is associated with additional risk of morbidity including scarring, gait disturbance, infection, nerve injury and the risk of the general anaesthetic and lower post-operative quality of life scores. ${ }^{14}$

A large amount of bone can be gained from the iliac crest (Fig. 3) and it can be sculpted to fit the recipient site. It is, however, relatively less dense than bone at the recipient site, with larger marrow spaces and this may be why it is more prone to resorption during the three to six month healing phase. The findings of a recent systematic review suggest that implants placed into sites augmented from the iliac crest have a higher failure rate compared to those placed into sites grafted from intraoral sites, ${ }^{10}$ however, this conclusion is drawn with some caution due to the risk of bias in the papers included.

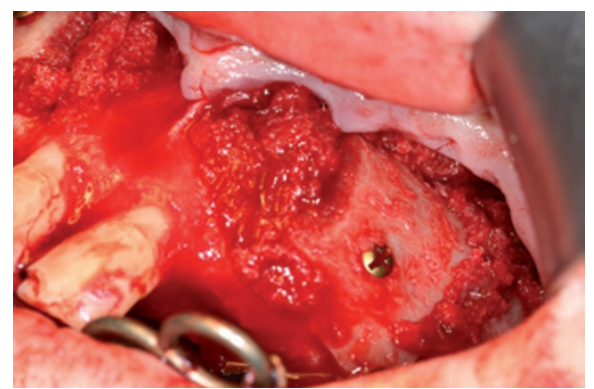

Fig. 3e Placement of cancellous bone chips around blocks

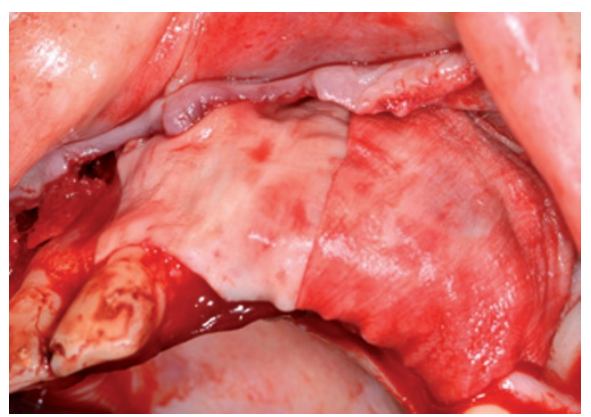

Fig. 3f Collagen membrane placed to stabilize bone chips and exclude soft tissue ingrowth

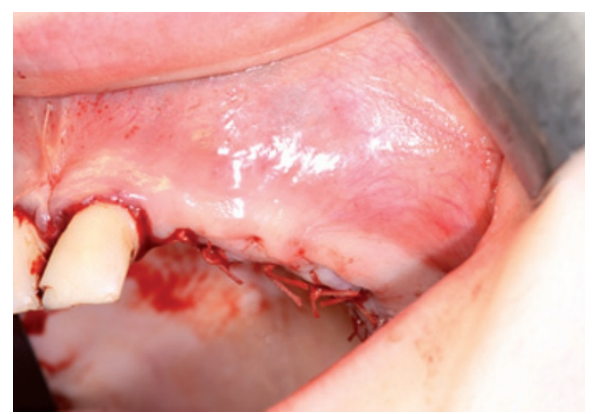

Fig. $3 \mathrm{~g}$ Careful closure of soft tissues after periosteal release

As previously described, soft tissue flap closure over the augmented area without tension is crucial to success, however, the more significant the change in ridge dimension, the more difficult this becomes.

\section{Maxillary sinus grafting}

In the posterior maxilla there is often minimal bone height for implant placement due to the size and position of the maxillary sinus. This is a particular problem in hypodontia cases where both premolars are absent and the primary molars are retained.

To overcome this difficulty maxillary sinus grafting can be performed (Fig. 4). This procedure traditionally involves accessing the maxillary sinus using a lateral approach, elevating the sinus membrane and augmenting bone beneath it. ${ }^{15}$ Implants placed following this have similar success rates to those placed conventionally ${ }^{16,17}$ and the procedure itself is well documented in the literature. Alternatively where only a limited height gain is required a localised 
sinus lift procedure can be carried out using osteotomes, ${ }^{18,19}$ although this is less well documented.

A recent systematic review concluded that where sinus augmentation is carried out, the evidence suggests that bone substitutes are as effective as the use of autogenous bone, ${ }^{20}$ although healing times are longer in the former. Use of bone substitutes means that there is no donor site and therefore postoperative discomfort and the risk of morbidity are likely to be reduced. Usually the procedure can be carried out under local anaesthetic on an outpatient basis in carefully selected cases.

This review also raises the question as to whether sinus augmentation is necessary at all. Shorter, wider implants (4 $\mathrm{mm}$ wide by $6 \mathrm{~mm}$ long) appear to be successful in the short term, although their longterm prognosis is unclear. ${ }^{21}$ The use of conventional length implants angled to avoid the sinus has been suggested as a way to avoid sinus grafting. ${ }^{22}$

This can be a viable alternative in a small number of cases, depending upon the position of adjacent teeth and implants. To ensure accurate placement in this situation it may be necessary to use a CT guided surgical stent. ${ }^{23}$

As described previously bone augmentation and implant placement can take place over a one or two stage procedure. Traditionally it has been suggested that if there is $4 \mathrm{~mm}$ or more of ridge height, implant placement can take place at the same times as sinus grafting (Fig. 5). However, as this is related to primary implant stability, the decision regarding staging should be taken on a case by case basis, depending on the quality of the bone, ${ }^{17,24}$ screw-thread morphology and surface characteristics of the implant system used.

\section{PROSTHODONTIC ASPECTS}

The use of dental implants should be restoratively driven rather than surgically driven to ensure the best treatment results. This means that the restorative dentist determines the ideal tooth position during the planning phase. Appropriately designed surgical guide stents are useful to ensure that implants are placed in the positions and at angulations to deliver this.

\section{Removable prostheses}

Although fixed implant supported prostheses may be ideal, in some cases where there are long edentulous spans and minimal alveolar bone, this may simply not be possible. Implant supported removable prostheses may provide an alternative that improves upon retention, stability and masticatory

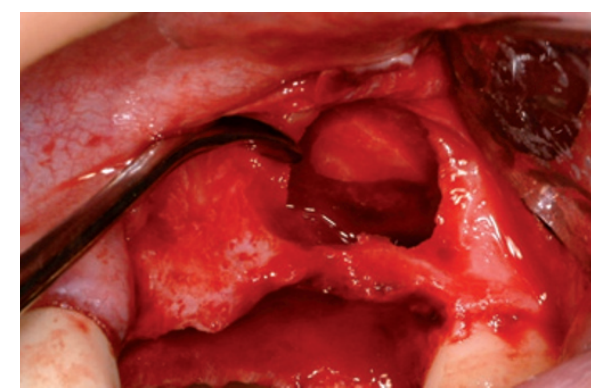

Fig. 4a Patient seen in Figure 1, undergoing lateral window preparation of left maxillary sinus and careful elevation of bony trap door and sinus lining

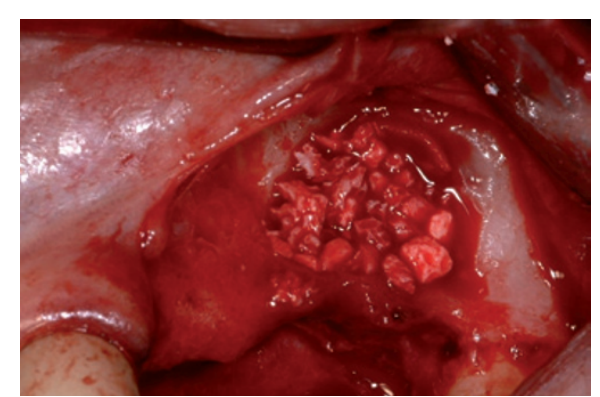

Fig. 4b Autogenous bone chips harvested via a disposable bone trap have been used together with large particles of xenograft to fill the space below the sinus lining and provide increased bone height

function. ${ }^{25,26}$ The placement of two fixtures in the anterior mandible to retain a lower overdenture has been shown to be a predictable solution, whereas in the maxilla more limited benefits have been shown. ${ }^{27}$

\section{Fixed prostheses}

The trends in implant treatment for this group of patients are to use fewer, moderate length implants in more controlled positions to support sectional prostheses, rather than full arch linked prostheses. If any natural teeth present are of limited prognosis, then planning should where possible take this into account so that the prosthetic arch can be extended if indicated.

Implant placement should not encroach upon the planned embrasure spaces and due consideration should be given to providing an adequate inter-implant and implanttooth distance in order to maintain alveolar bone and papilla levels. ${ }^{28,29}$ Implant position and angulations will also be affected by the decision to provide either a cemented or screw retained fixed prosthesis (Figs 5 and 6).

Consideration should be given to the choice of material for the supra-structure of the restoration. In recent years, CAD CAM titanium and zirconium frameworks have become more widely available and a more accurate fit can be achieved when compared to cast metal frameworks. ${ }^{30,31}$ A recent systematic review reports that conventional

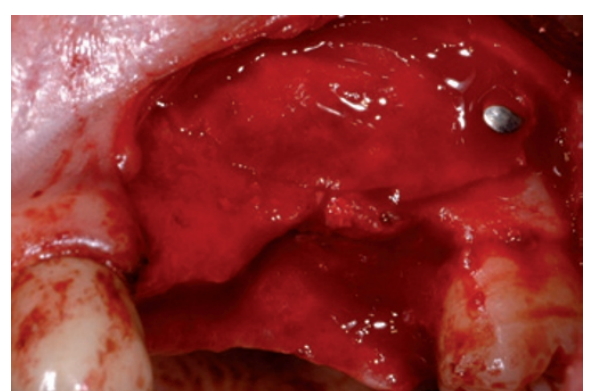

Fig. 4c Xenograft collagen membrane placed over lateral window and secured with titanium tacks

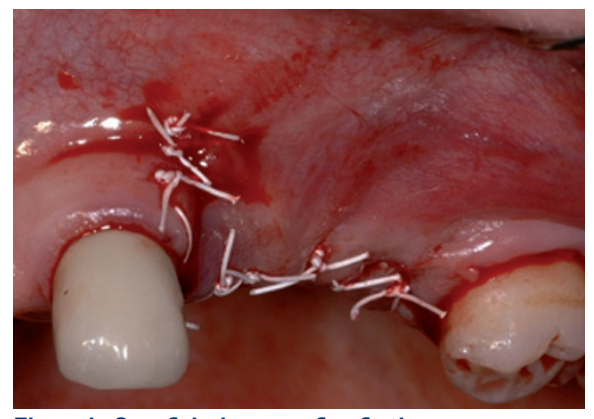

Fig. 4d Careful closure of soft tissues and six month healing period before implant placement

metal ceramic supra-structures continue to have the advantage in terms of durability related to chipping of the veneering porcelain and cost in comparison to zirconia alternatives. $^{32}$ Due to the higher wear resistance of porcelain this may be the most appropriate choice where the opposing arch is natural teeth or porcelain. Alternatively, where the opposing prosthesis is acrylic, it would be more appropriate to provide acrylic or composite occlusal surfaces, due to the matched wear characteristics of these materials.

\section{Long-term maintenance}

Small sections of bridgework can be used to replace multiple missing teeth if the supporting implants are strategically placed. In this situation, should technical complications occur, the restoration is more retrievable and maintainable than if a full arch fixed prosthesis was present. This is especially important in young patients, who are likely to require the repair or replacement of the implant supra-structure at some point during their lifetimes. To further aid this, where aesthetics allow, screw retained prostheses should be used in preference to cement retained. ${ }^{33}$

The minor chipping or bulk fracture of porcelain on metal ceramic or zirconia prostheses is a documented risk. ${ }^{32,34} \mathrm{~A}$ number of proprietary chairside porcelain repair kits are available, ${ }^{35}$ although the long-term success of these remains 


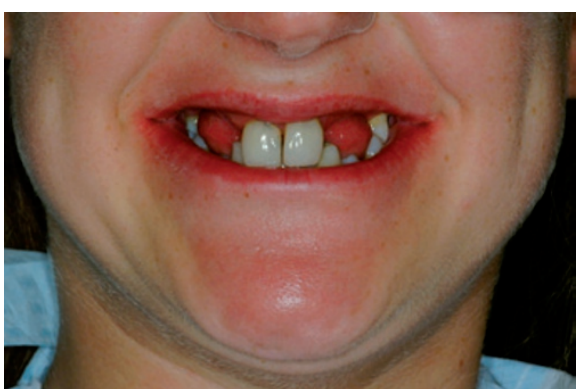

Fig. 5a A 25-year-old female with 17 missing adult teeth and failing retained primary teeth

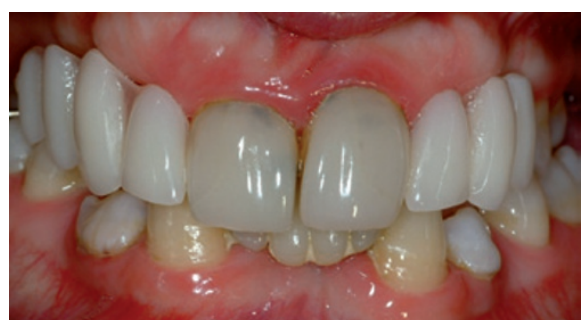

Fig. $5 \mathrm{~b}$ Initially treated with adhesive bridges many years earlier and then latterly with extractions and an acrylic upper partial denture

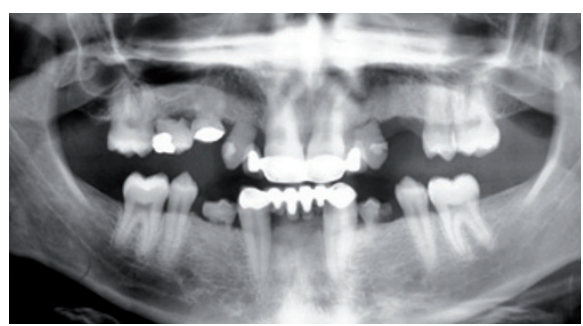

Fig. 5c Panoramic radiograph of initial presentation demonstrating failing primary teeth and inadequate bone height in right maxillary region (approximately $4 \mathrm{~mm}$ )

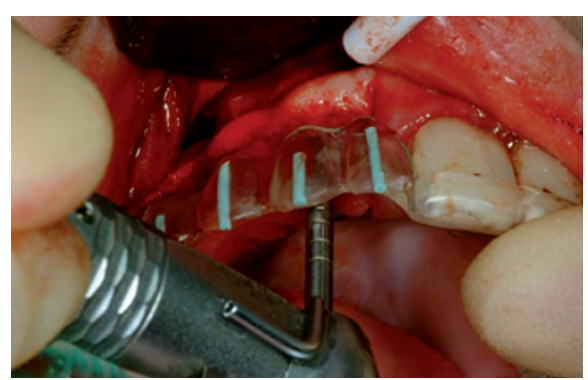

Fig. $5 \mathrm{~d}$ Use of surgical/radiographic guide stent to assist in precise implant positioning at surgery with respect to planned tooth position

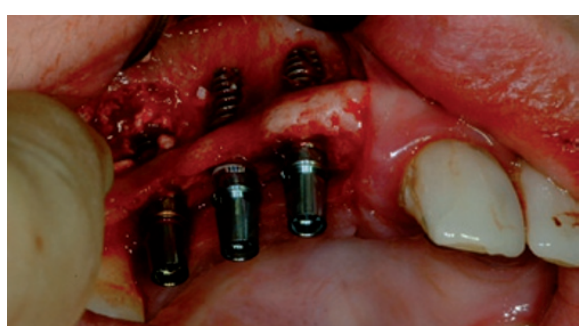

Fig. 5e Right maxillary sinus graft and simultaneous placement of dental implants in $13,14,15$ region using autogenous bone chips, xenograft particles and membrane for sinus and buccal ridge augmentation

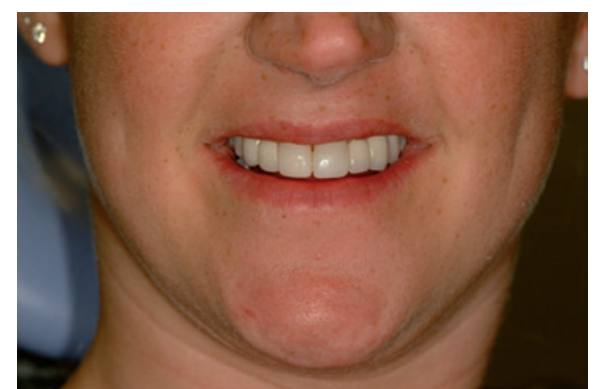

Fig. $5 f$ Extraoral view of completed restorative treatment

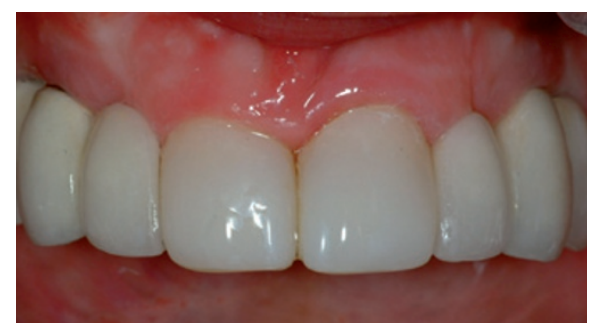

Fig. $5 \mathrm{~g}$ Removal of old porcelain veneers and then direct composite bonding to 11,21

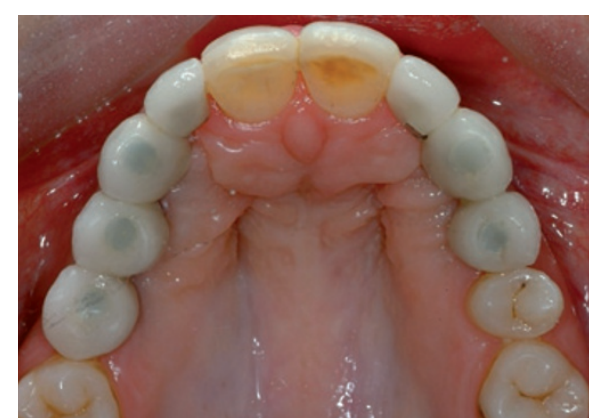

Fig. 5h Screw-retained implant bridges 12, $13,14,22,23,24$ and implant crown 15

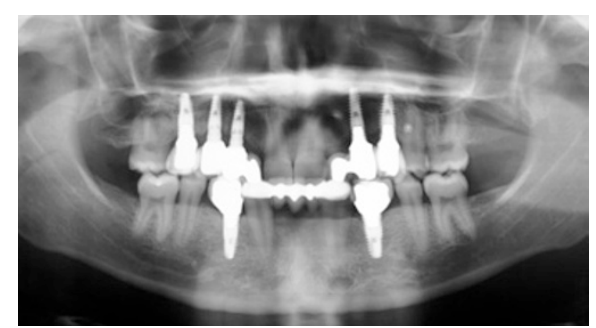

Fig. 5i Panoramic radiograph of completed case demonstrating gain in bone height in right maxilla for placement of dental implants. The implants in both right and left maxilla required extensive guided bone regeneration to facilitate their placement in the correct positions. Composite bonding was also carried out to improve the size and shape of the lower canines before provision of a new adhesive bridge anteriorly and implant crowns in the lower premolar region

unpredictable. For this reason, some clinicians consider that acrylic/metal suprastructures are preferable as they are more easily repaired chairside with the use of composite bonding. However, as these materials are more susceptible to attritive wear and the uptake of stains, the acrylic work is likely to need replacement more frequently than ceramic alternatives.

Several methods and regimes have been proposed to prevent and treat peri-implant mucositis and peri-implantitis and these were evaluated in two recent Cochrane reviews. ${ }^{36,37}$ Although the role of plaque in the aetiology of these conditions is well established, ${ }^{38}$ the literature is of insufficient quality to conclude that one preventative or treatment regime is the best.

As with conventional fixed prostheses, implant prostheses should be designed to facilitate oral hygiene measures. This includes ensuring that emergence profile is not excessively bulky and pontic surfaces and interproximal contact areas are cleansable for the patient, on a daily basis, with interdental cleaning aids. The prostheses should also allow easy access for regular examination of the peri-implant soft tissues with a periodontal probe and for professional debridement both supra- and sub-gingivally to remove any plaque retentive deposits and disturb the biofilm. ${ }^{39}$ At times it may be necessary to accept a compromise in aesthetics in order to facilitate the long-term maintenance of periimplant health. If patients are appropriately selected and prostheses carefully designed and constructed, these should be easily maintained within a general dental practice environment.

\section{CONCLUSION}

In cases of severe hypodontia, the focus in childhood and adolescence should be on prevention and maintenance of the primary dentition where possible. Definitive treatment options are likely to be complicated by a lack of ridge height and width, small teeth of poor morphology and unfavourable skeletal and soft tissues patterns, which make the provision of conventional prostheses difficult or impossible in many cases. Providing implant-supported prostheses is also unlikely to be straightforward, often requiring bone augmentation. Treatment may stretch over many years involving a number of invasive procedures, each of them carrying some risk of morbidity. In complex cases the involvement of a multidisciplinary team is needed to improve outcome.

With careful planning, patients with severe hypodontia can be rehabilitated very effectively in most cases achieving a good functional and aesthetic result. It should be highlighted that these patients will require ongoing follow up, maintenance and retreatment procedures over their lifetimes. Further research into new techniques to improve the hard and soft tissue foundations before implant treatment is needed.

1. Bondarets N, McDonald F. Analysis of the vertical facial form in patients with severe hypodontia. Am J 

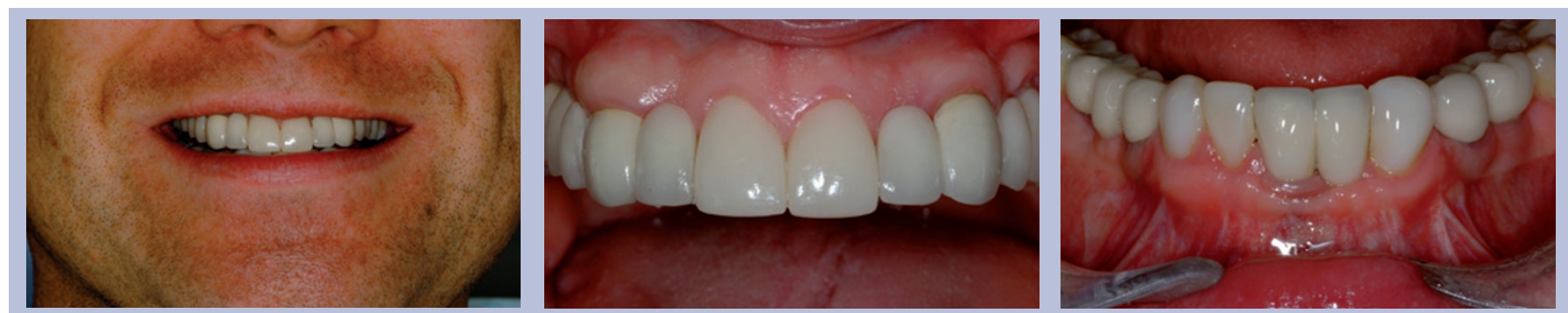

Figs $6 a-c$ Completed restorative treatment of patient shown in Figure 1

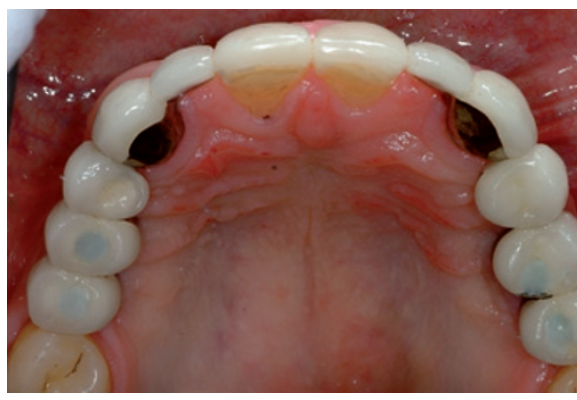

Fig. 6d Upper arch treated with porcelain veneers 11,21 , conventional cantilever bridges 12,13 and 22, 23. Screw-retained implant bridges 14, 15, 16 and 24, 25, 26

Phys Anthropol 2000; 111: 177-184

2. von Arx T, Buser D. Horizontal ridge augmentation using autogenous block grafts and the guided bone regeneration technique with collagen membranes: a clinical study with 42 patients. Clin Oral Implants Res 2006: 17: 359-366.

3. Esposito M, Grusovin M G, Felice P, Karatzopoulos G, Worthington HV, Coulthard P. The efficacy of horizontal and vertical bone augmentation procedures for dental implants - a Cochrane systematic review. Eur J Oral Implantol 2009; 2: 167-184.

4. Cawood J I, Stoelinga P J, Brouns J J. Reconstruction of the severely resorbed (Class VI) maxilla. A twostep procedure. Int J Oral Maxillofac Surg 1994; 23: 219-225.

5. Esposito M, Grusovin M G, Chew Y S, Coulthard $P$, Worthington H V. One-stage versus two-stage implant placement. A Cochrane systematic review of randomised controlled clinical trials. Eur J Oral Implantol 2009: 2: 91-99.

6. Becker W. Treatment of small defects adjacent to oral implants with various biomaterials. Periodontol 2000 2003; 33: 26-35.

7. Young M P, Carter D H, Worthington $H$, Korachi $M$, Drucker D B. Microbial analysis of bone collected during implant surgery: a clinical and laboratory study. Clin Oral Implants Res 2001; 12: 95-103.

8. Blay A, Tunchel S, Sendyk W R. Viability of autogenous bone grafts obtained by using bone collectors: histological and microbiological study. Pesqui Odontol Brasil 2003; 17: 234-240.

9. Etcheson A W, Miley D D, Gillespie M J. Osseous coagulum collected in bone traps: potential for bacterial contamination and methods for decontamination. J Oral Implantol 2007; 33: 109-115.

10. Chiapasco M, Casentini P, Zaniboni M. Bone augmentation procedures in implant dentistry. Int J Oral Maxillofac Implants 2009; 24 Suppl: 237-259.

11. Joshi A. An investigation of post-operative morbidity following chin graft surgery. Br Dent J 2004; 196: 215-218.

12. Pereira C C, Gealh W C, Nogueira L M, Garcia Junior I R, Okamoto R. Piezosurgey applied to implant dentistry: clinical and biological aspects. J Oral Implantol 2012; epub ahead of print.

13. Buser D, Dula K, Belser U C, Hirt H P, Berthold H. Localized ridge augmentation using guided bone regeneration. II. Surgical procedure in the mandible. Int J Periodontics Restorative Dent 1995; 15: 10-29. 14. Reissmann D R, Dietze B, Vogeler M, Schmelzeisen

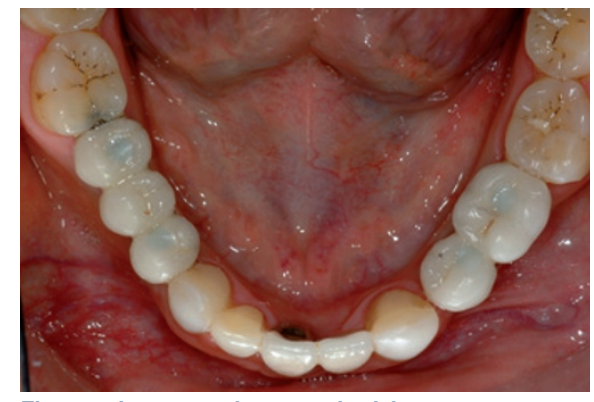

Fig. 6e Lower arch treated with screwretained implant bridges $31,32,44,45,46$ and implant crowns 34,35 with composite bonding to 42,43 and 33

R, Heydecke G. Impact of donor site for bone graft harvesting for dental implants on health-related and oral health-related quality of life. Clin Oral implants Res 2013; 24: 698-705.

15. Boyne P J, James R A. Grafting of the maxillary sinus floor with autogenous marrow and bone. J Oral Surg 1980; 38: 613-616.

16. Aghaloo T L, Moy P K. Which hard tissue augmentation techniques are the most successful in furnishing bony support for implant placement? Int J Oral Maxillofac Implants 2007; 22 Suppl: 49-70.

17. Jensen S S, Terheyden H. Bone augmentation procedures in localized defects in the alveolar ridge: clinical results with different bone grafts and bonesubstitute materials. Int J Oral Maxillofac Implants 2009; 24 Suppl: 218-236.

18. Summers R B. The osteotome technique: part 3 less invasive methods of elevating the sinus floor. Compendium 1994; 15: 698, 700, 702-704.

19. Raja S V. Management of the posterior maxilla with sinus lift: review of techniques. J Oral Maxillofac Surg 2009; 67: 1730-1734.

20. Esposito M, Grusovin M G, Rees J et al. Effectiveness of sinus lift procedures for dental implant rehabilitation: a Cochrane systematic review. Eur J Oral Implantol 2010; 3: 7-26.

21. Esposito M, Cannizzaro G, Soardi E et al. Posterior atrophic jaws rehabilitated with prostheses supported by $6 \mathrm{~mm}$-long, $4 \mathrm{~mm}$-wide implants or by longer implants in augmented bone. Preliminary results from a pilot randomised controlled trial. Eur Oral Implantol 2012; 5: 19-33.

22. Aparicio $C$, Perales $P$, Rangert B. Tilted implants as an alternative to maxillary sinus grafting: a clinical, radiologic, and periotest study. Clin Implant Dent Relat Res 2001; 3: 39-49.

23. Widmann G, Bale R J. Accuracy in computer-aided implant surgery-a review. Int J Oral Maxillofac Implants 2006; 21: 305-313.

24. Dos Santos M V, Elias C N, Cavalcanti Lima J H. The effects of superficial roughness and design on the primary stability of dental implants. Clin Implant Dent Relat Res 2011; 13: 215-223.

25. Fueki K, Kimoto K, Ogawa T, Garrett N R. Effect of implant-supported or retained dentures on masticatory performance: a systematic review. J Prosthet Dent 2007; 98: 470-477.

26. Thomason J M, Kelly S A, Bendkowski A, Ellis J S. Two implant retained overdentures-a review of the literature supporting the McGill and York consensus

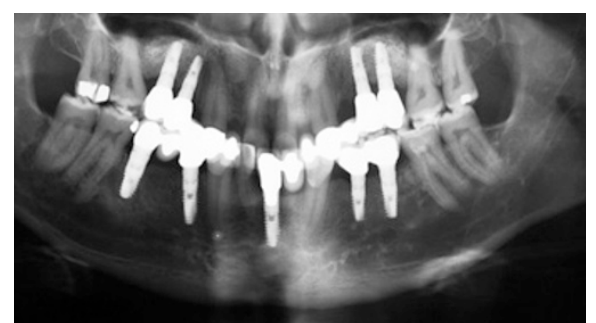

Fig. 6f Panoramic radiograph of completed case

statements. J Dent 2012; 40: 22-34

27. Sadowsky S J. Treatment considerations for maxillary implant overdentures: a systematic review. J Prosthet Dent 2007: 97: 340-348.

28. Tarnow D P, Cho S C, Wallace S S. The effect of interimplant distance on the height of inter-implant bone crest. J Periodontal 2000; 71: 546-549.

29. Choquet $V$, Hermans $M$, Adriaenssens $P$, Daelemans P, Tarnow D P, Malevez C. Clinical and radiographic evaluation of the papilla level adjacent to singletooth dental implants. A retrospective study in the maxillary anterior region. J Periodontal 2001; 72: 1364-1371.

30. Abduo J, Lyons K, Bennani V, Waddell N, Swain M Fit of screw-retained fixed implant frameworks fabricated by different methods: a systematic review. Int J Prosthodont 2011; 24: 207-220.

31. Abduo J, Lyons K, Waddell N, Bennani V, Swain M. A comparison of fit of CNC-milled titanium and zirconia frameworks to implants. Clin Implant Dent Relat Res 2012; 14(Suppl 1): e20-29.

32. Heintze S D, Rousson V. Survival of zirconia-and metalsupported fixed dental prostheses: a systematic review. Int J Prosthodont 2010; 23: 493-502.

33. Michalakis KX Hirayama $H$, Garefis P D. Cementretained versus screw-retained implant restorations: a critical review. Int J Oral Maxillofac Implants 2003; 18: 719-728.

34. Pjetursson B E, Bragger U, Lang N P, Zwahlen M. Comparison of survival and complication rates of tooth-supported fixed dental prostheses (FDPs) and implant-supported FDPs and single crowns (SCs). Clin Oral implants Res 2007; 18(Suppl 3): 97-113.

35. Blum I R, Jagger D C, Wilson N H. Defective dental restorations: to repair or not to repair? Part 2: Allceramics and porcelain fused to metal systems. Dent Update 2011; 38: 150-152, 154-156, 158.

36. Esposito M, Maghaireh $H$, Grusovin M G, Ziounas I, Worthington H V. Soft tissue management for dental implants: what are the most effective techniques? A Cochrane systematic review. Eur J Oral Implantol 2012; 5: 221-238.

37. Esposito M, Grusovin M G, Worthington H V. Treatment of peri-implantitis: what interventions are effective? A Cochrane systematic review. Eur J Oral Implantol 2012; 5 Suppl: S21-41.

38. Pontoriero R, Tonelli M P, Carnevale G, Mombelli A, Nyman S R, Lang N P. Experimentally induced peri-implant mucositis. A clinical study in humans. Clin Oral Implants Res 1994; 5: 254-259.

39. Esposito M, Hirsch J, Lekholm U, Thomsen P. Differential diagnosis and treatment strategies for biologic complications and failing oral implants: a review of the literature. Int J Oral Maxillofac Implants 1999; 14: 473-490. 